\title{
An Open-Circuit Fault Detection Method with Wavelet Transform In IGBT-Based DC/AC Inverter Used in Electric Vehicles
}

\author{
S. S. Moosavi ${ }^{1}$, Hesam Akbari ${ }^{2}$, Saeed Valipour ${ }^{3}$ \\ ${ }^{1}$ Amol University of Special Modern Technologies, Amol, Iran \\ ${ }^{2}$ University of Kavosh, Department of Engineering, Amol, Iran \\ ${ }^{3}$ Iran University of Science and Technology (IUST), Tehran, Iran
}

\begin{tabular}{l}
\hline \hline Article Info \\
\hline Article history: \\
Received Oct 23, 2017 \\
Revised Dec 7, 2017 \\
Accepted Jul 1, 2018 \\
\hline
\end{tabular}

\section{Keyword:}

Artificial neural network

(ANN)

Electric vehicles (EV)

Fault diagnosis (FD)

Open-circuit faults

Voltage source inverter (VSI)

Wavelet transform (WT)

\begin{abstract}
Today power electronics play an important role in the electric industry. Power electronic converters are an inseparable component in power systems. One of these converters is DC/AC inverter that is widely used in power systems, industrial applications, electric motor drive and electric vehicles. Due to the tense situation with the complexity that exists in these applications, inverters are exposed to failure. The fault occurring in inverter can cause disturbance and damaging harmonics, cut some industrial processes to in the power system or in the case of electric vehicles, causing irreparable damage. For this reason, detecting faults in the inverter is very important. In this paper, open circuit fault of IGBT in an electric vehicle has been examined. We use three-phase current and wavelet transform to identify the state of the system and we can extract current waveform characteristics. We use neural network algorithm for fault detection and classification. An electric vehicle in 5 different speeds and 5 different torque and a total of 220 failure modes have been studied and tested. The results show the method has been succeeded to detection all forms of defined faults.
\end{abstract}

Copyright $\odot 2018$ Institute of Advanced Engineering and Science. All rights reserved.

\section{Corresponding Author:}

Seyed Saeid Moosavi,

Departement of Electrical and Computer Engineering,

Amol University of special modern technologies, Amol, Iran

Email: anchepoli@gmail.com

\section{INTRODUCTION}

DC/AC inverters are one of the most important components in power systems. The most common of these inverters are voltage source inverters with IGBT switching elements that are widely used in power systems, industrial processes, electrical distribution systems and other electric vehicles [1-5]. Due to the tense environment with complex conditions and heavy work in these applications, the inverters are always subject to failure so that cause distortion and harmonics destructive power system, or disrupted in some industrial processes. In electric vehicles, this fault can cause irreparable damages. Therefore, fault detection and diagnosis in the inverter are very important [6]. Recently, in a survey about the systems of industrial power electronics, $31 \%$ of respondents chose "power device semiconductor" as one of the most fragile components. This is the importance of studying reliability, identifying and controlling the faults [2,3]. However, these devices are not reliable enough during their use, so preventing and predicting the maintenance actions can be significant [5].

Among the faults that occurred in the inverter, detecting open-circuit fault is very important. Because in the event of fault, the system does not change much and the system continues to work with a disturbance. Over time, this fault expands and will cause serious damage to the power system. For this reason, many researchers have been tried to identify and study about this fault. In References [7, 8], fault 
detection and locating defective switches have done by analysing the direction of the vector space. But this approach has serious problems such as incorrect timing and accuracy. References [9] used Park vector method for fault detecting in voltage source inverter and have successfully implemented it. However, this method requires a very complex pattern of the algorithm that is not suitable to run on the controller drives. Also at low currents, this approach loses its capabilities.

References [10, 11] used voltage-based methods for early fault detection. However, this method needs voltage sensors that are expensive and more complex. In addition, to prevent false alarms, some delay time must be properly defined and since there are several variables, it may cause complexity in the system. A cascaded multi-layered strategy to fault identification in inverters is proposed in [6], which consists of two parts. The first part is analysing output voltage and inverter current signal. When the open-circuit fault in the switch transistors occurs, the output voltage waveform is analysed to extract fault feature. The second part includes extraction and classification of fault features using the FFT-RPCA-SVM method. The FFT is used for the signal feature extraction. The relative principal component analysis (RPCA) is used to optimize and reduce the data and finally, SVM classification method is used to classifying the data. But this paper is useful only for pure R loads systems, in the event that, most loads in the power system are the type RL. Also, The FFT method is used for signal analysis. This method doesn't have good performance in transient state and cannot detect the fault severity and the time of occurrence. This makes problems for the user during controlling of fault. A new method for classification and detection of an open-circuit fault in the electric motor factory have been examined in Ref. [12]. The method is using a combination of wavelet transforms, Fourier transform and neural network. Both wavelet transform (WT) and Fourier transform (FFT) are strong and useful for analysing electrical systems. But combining these two methods doesn't have benefit in analysing. Also, in this paper, using FFT analysis after WT has no effect on transient state and makes analysing difficult.

In this paper, open-circuit fault identification and detection in the DC/AC converter has been done by application in electric vehicles. Proposed Electric Vehicle has DC/DC converter configuration with multiple inputs. Proposed inverter is voltage source type and PMSM motor with vector control drive is chosen. The method used to fault detection is a combination of discrete wavelet transform and multi-layered neural network. All expected open circuit fault positions in the operating conditions have been studied in this paper. The structure of the paper is as follows: In section II, the structure of the electric vehicle is proposed. In section III, detecting open-circuit fault is provided. In section IV, Artificial Neural Network will introduce. Section V present the research results and section VI concludes this paper.

\section{RESEARCH THE STRUCTURE OF THE ELECTRIC VEHICLE}

According to Energy Outlook in 2011, the share of fuel consumption in the transportation sector raised from $40 \%$ in 2008 to 54\% [4]. The projections carried out by the Energy International Agency (EIA) represents an increase of $\$ 5.5$ gallons of oil prices at the highest rate possible. Also due to global warming and climate change, it is expected that technologies that reduce fuel consumption in the transportation sector such as electric vehicles and hybrid vehicles will find a better position among other [6].

\subsection{Proposed System Characteristic}

Due to the high price of the fuel cell, bad Dynamic mode response and expensiveness of supplying hydrogen, electric vehicles studied in this paper uses the battery as the primary source of energy and super capacitors as an auxiliary source. Using fuel cells instead of batteries greatly reduces the final price of the car. Also it enables the car to use both sources at the first of start-up [13].

The configuration of the car is multiple-input converter which is a DC/DC power electronics multilayer converter topology as it is shown in Figure1. Using the DC/DC converter with multiple inputs reduces costs and the amount of energy in the system. Also, the multilayer converter topology reduces the output ripple voltage and current will directly affect the lifespan of energy resources and thereby extend the life of the equipment. Also, passive elements such as inductors, which are the main concern in the design of DC/DC converters is reduced and thus the size and weight of the converter is optimized. In this configuration, the battery connected to the DC bus with the one-way DC/DC converter and super capacitors connected to the bus by a bidirectional DC/DC converter, so that the energy from braking performance, is stored in super capacitors $[14,15]$.

We used a DC/AC inverter with an electric motor for motion part. PMSM is connected to the front wheels by the inverter. A voltage source inverter (VSI) topology is used in this paper, which has a multi-level topology and is equipped with 6 members IGBT switching. The benefits of this inverter are better stabilized output voltage, low harmonic distortion, variable output voltage and frequency. Also, this plan is useful due 
to low impedance, constant input, and output voltage as well as for performance in single or multiple electric motors [16].

\subsection{PMSM with Vector Control Drive}

Vector control or FOC (field oriented control) is a method that capable of isolating torque from flux that seems to be the best alternative to methods of controlling PMSM motor drive. The aim of FOC control is controlling torque, mechanical speed changes and also regulating stator current during transient flow in the system [17]. The FOC is used for control strategy, providing a stator current that expresses axis D-Q in synchronous rotation [18]. PMSM equations in the reference axis D-Q is expressed as follows:

$\frac{d_{i s d}}{d_{t}}=-\frac{R_{s}}{L_{d}} i_{s d}+\omega_{r} \frac{L_{q}}{L_{d}} i_{s q}+\frac{V_{s d}}{L_{d}}$

$\frac{d_{i s q}}{d_{t}}=-\frac{R_{s}}{L_{q}} i_{s q}-\omega_{r} \frac{L_{d}}{L_{q}} i_{s d}-\omega_{r} \frac{\Psi_{f}}{L_{d}}+\frac{V_{s d}}{L_{d}}$

$\Psi_{\text {sd }}=\mathrm{L}_{\mathrm{d}} \mathrm{i}_{\mathrm{sd}}+\Psi_{\mathrm{f}}$

$\Psi_{\mathrm{sq}}=\mathrm{L}_{\mathrm{q}} \mathrm{i}_{\mathrm{sq}}$

In the above equations, Rs is stator resistance, id and iq are the D-Q axis current, $\mathrm{Vd}$ and $\mathrm{Vq}$ are $\mathrm{D}$ $\mathrm{Q}$ axis voltage, Lq, Ld are D-Q axis inductances, $\omega r$ is angular speed, $\Psi$ sd and $\Psi$ sq are D-Q flux axial, $\Psi f$ is magnetic flux produced there.

Electromagnetic torque and rotor position are as follows:

$\mathrm{T}_{\mathrm{e}}=\frac{3}{2} \mathrm{P}\left[\left(\mathrm{L}_{\mathrm{d}}-\mathrm{L}_{\mathrm{q}}\right) \mathrm{i}_{\mathrm{sd}} \mathrm{i}_{\mathrm{sq}}+\mathrm{i}_{\mathrm{sq}} \Psi_{\mathrm{f}}\right]$

$\theta_{\mathrm{r}}=\frac{\mathrm{P}}{2 \mathrm{~J}}\left[\mathrm{~T}_{\mathrm{e}}-\frac{2}{\mathrm{P}} \beta_{\mathrm{f}} \omega_{\mathrm{r}}-\mathrm{T}_{\mathrm{L}}\right]$

In the above equations, $\mathrm{P}$ is the number of pole pairs, $\mathrm{J}$ is the coefficient of inertia, TL is load factor and $\beta \mathrm{f}$ is the effect of friction. Since the electromagnetic torque is linear and related to isq, it is simplified as follows [19]:

$\mathrm{T}_{\mathrm{e}}=\frac{3}{2} \mathrm{Pi}_{\mathrm{sq}} \Psi_{\mathrm{f}}=\mathrm{K}_{\mathrm{t}} \mathrm{i}_{\mathrm{sq}}$

\section{OPEN-CIRCUIT FAULT DETECTION}

The inverter that used in this vehicle is a three-level voltage source inverter type with six IGBT switching element. The benefits of the inverter can be mentioned better output voltage, simpler topology, cheap, low harmonic distortion, and easier control. Proposed electric vehicle configuration is shown in Figure 1. The internal structure of the electric vehicle study is shown in Figure 2.

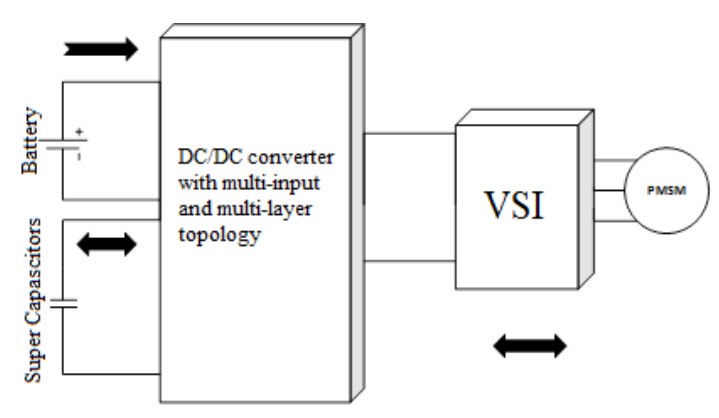

Figure 1. Proposed electric vehicle configuration 


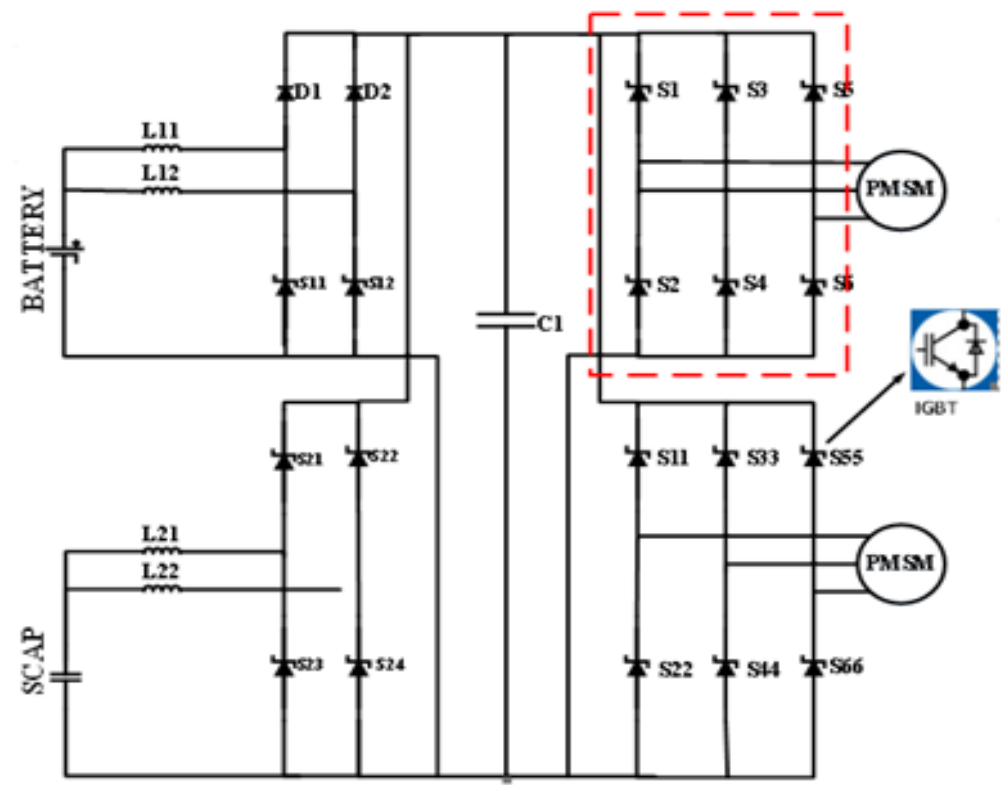

Figure 2. Proposed electric vehicle structure

\subsection{Introducing Healthy and Faulty Component of Inverter}

An integrated fault management system includes system protection, fault detection, isolation and diagnosis and reconfigure the system with control units. In general, the structure of the fault detection and identification systems begins by measuring parameters such as current, voltage, speed and torque. These parameters include operating under different fault conditions. To detect and identify fault we need special features. With the help of these features, the extracted signal can be analysed to detect faults and identify its type [20].

In this paper, WT has been used for feature extraction of three-phase current signal. The advantage of using wavelet transform instead of Fourier or other analysis methods based on the frequency signal is the availability of WT to analyse the system even in non-stationary mode.

Under normal operating conditions, in non-stationary state of speed and torque, Fourier and other frequency methods have the less efficient information and the severity and time of occurrence of the faults cannot be extracted properly [21]. It should be noted that if more than four IGBT circuit gets faulty, the inverter cannot operate and cannot supply the requirement power for the electric motor. Also, if more than three IGBT circuit gets faulty, the current system gets 3 times of the amount of their rated current, and this current increasing is identifiable by a security system and will make the system isolate to the fault. That's why in this article only single and double switches fault have been studied. The system has been analysed in different speed and loads for healthy and faulty states of S1, S2 ... .S6, S1S2 .. S3S4... S5S6. The target system has been tested in 26 cases. In this paper, wavelet transformation in 12 levels by the mother wavelet of $45 \mathrm{db}$ for current signal analysis is used. In this work EV studied under different conditions with 5 levels of torque and speed separately has been studied and evaluated a total of 220 different modes. Three-phase current waveform in a healthy state and the faulty state is shown in Figure 3 and 4.

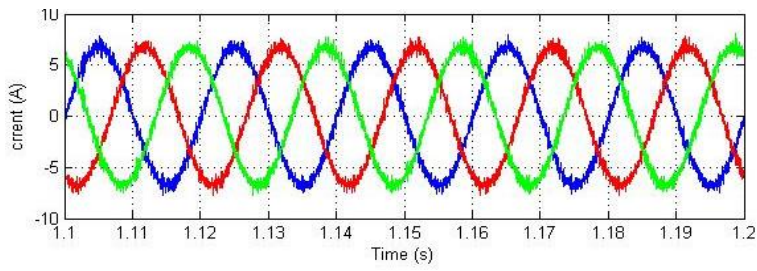

(a)

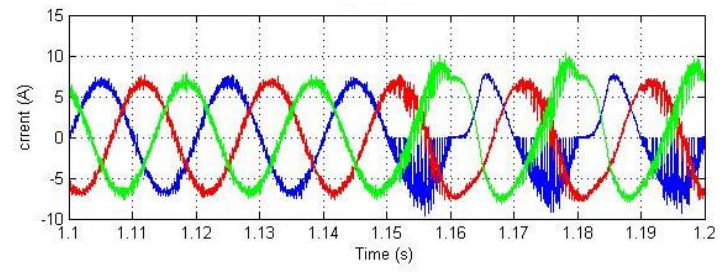

(b)

Figure 3. Three phase current for 550rpm and 7.5n.m in a) healthy mod b) S1 open-circuit fault 


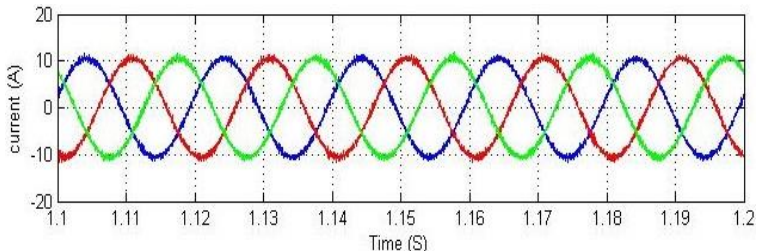

(a)

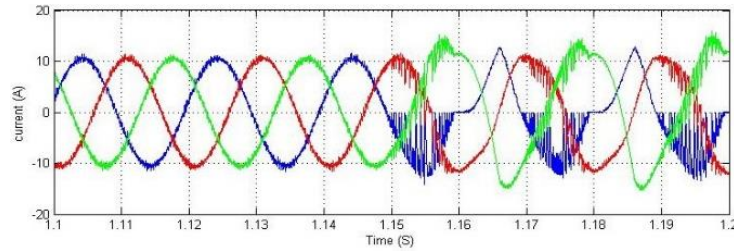

(b)

Figure 4. Three phase current for 750rpm and 11.5n.m in a) healthy mod b) S1 open-circuit fault

Figure 5 shows the results of wavelet transform in the static state of electric vehicles in healthy and faulty operating conditions.
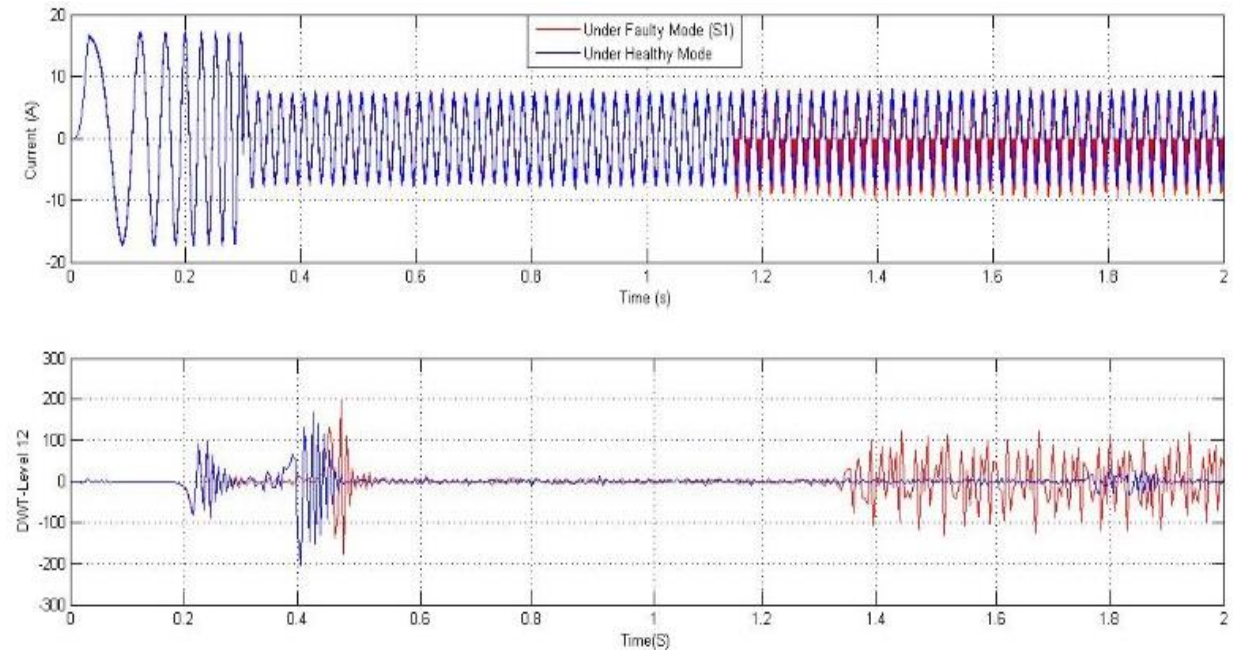

Figure 5. Wavelet transform in healthy and S1 open-circuit fault

\subsection{Open Circuit Fault Detection Pattern}

In order to more effective analysis and to achieve the best fault characteristics the wavelet transform has been implemented. Also, unlike other methods based on the frequency signal analysis, wavelet transform has good performance under transient conditions and system stability; this feature is a great advantage to other methods of signal analysis.

In this paper, the mean energy has been used as a pattern introduced for extracting the characteristic that is simple, fast and works in different operating states. The mean energy can be obtained from Equation. 8 .

$$
\text { Mean Energy }=\sqrt{\sum_{\mathrm{l}=0}^{\mathrm{n}} \frac{\left|\mathrm{D}_{\mathrm{i}}\right|^{2}}{\mathrm{~L}}}
$$

Where, $D_{i}$ is the $i^{\text {th }}$ wavelet data signals and $L$ is the range and number of data in the healthy state. The output of this equation is a number that used to train the neural network. In Figure. 7 and 8 performance of suggested fault pattern under load and speed variation are shown. According to shown figures, the suggested model could well extract any fault in both stationary and non-stationary state of vehicle operation. 

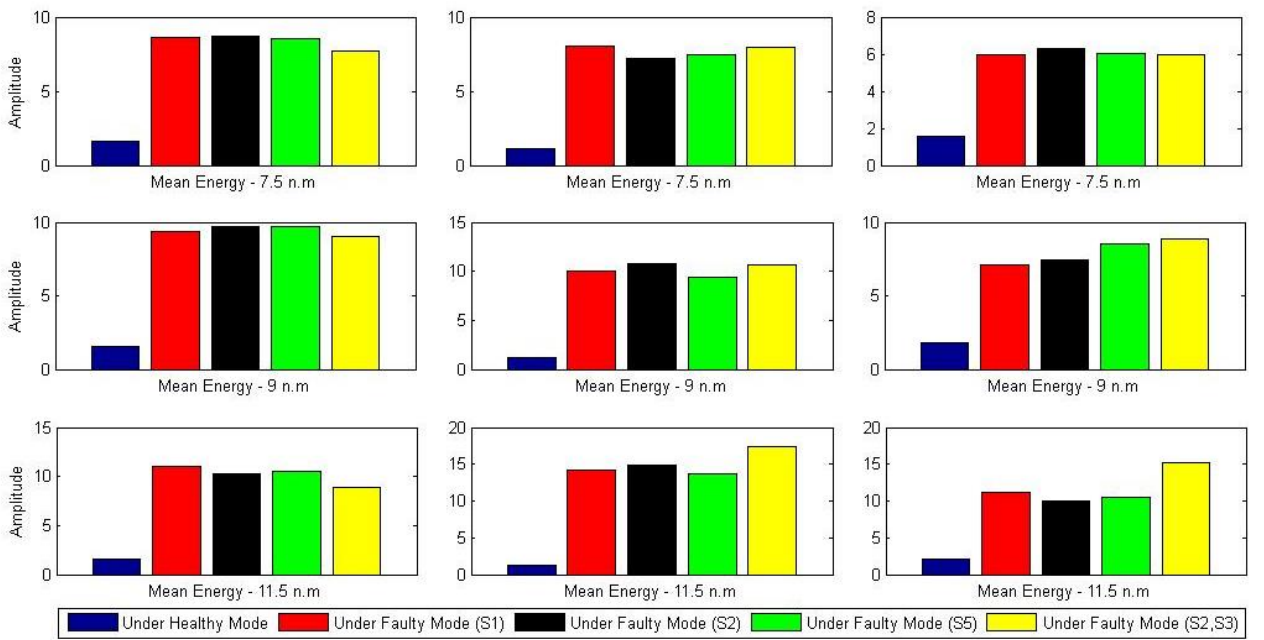

Figure 6. The effect of load variation on different faults and performance of proposed fault detection
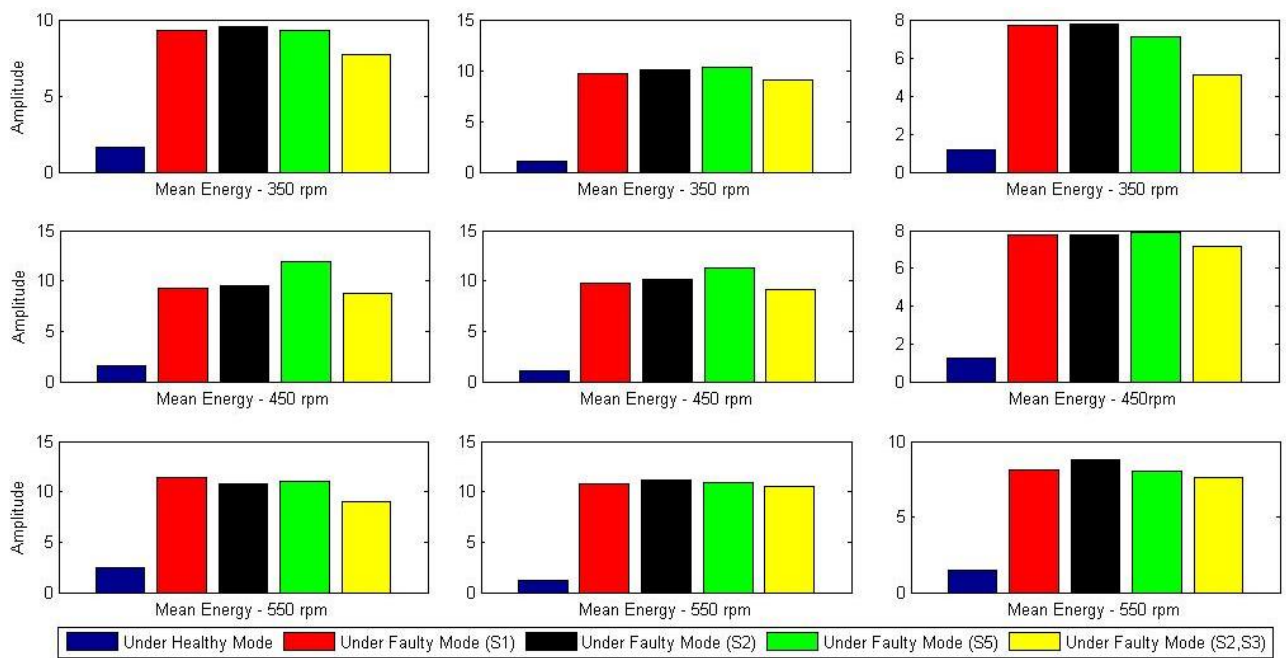

Figure 7. The effect of speed variation on different faults and performance of proposed fault detection

In this part, these states are evaluated in order to display the nonlinear relationship. According to the nonlinear relation between data that shown in Figure 8 and 9 and good performance of the neural network in solving nonlinear relations, using the neural network for achieving to target is justified.

\section{FAULT DETECTING USING NEURAL NETWORK}

\subsection{Multilayer Neural Network}

Recently, methods based on the artificial neural network are using for fault detection and identification. Neural networks have some advantages such as less statistical training, Ability to identify complex relations between independent and dependent variables faults, ability to detect all the possible interactions between predictor variables detection. But this algorithm requires a very special and heavy training that a process is very strict. It is considered one of the disadvantages of neural network algorithms [22-26]. Overlap between neural network training in different speeds is shown in Figure 8, and Overlap between neural network training in different loads is shown in Figure 9.

This neural network include three layers of input, output and hidden layer. The output of the first layer, considered as the second layer input vector. Similarly, the output of the second layer is input vector of the third layer. The output of the second layer shows the actual response of the network. There are many types of neural networks, but usually, a type of neural network is a multilayer feed forward neural network that is used a lot. An example of this neural network is shown in Figure 10. 

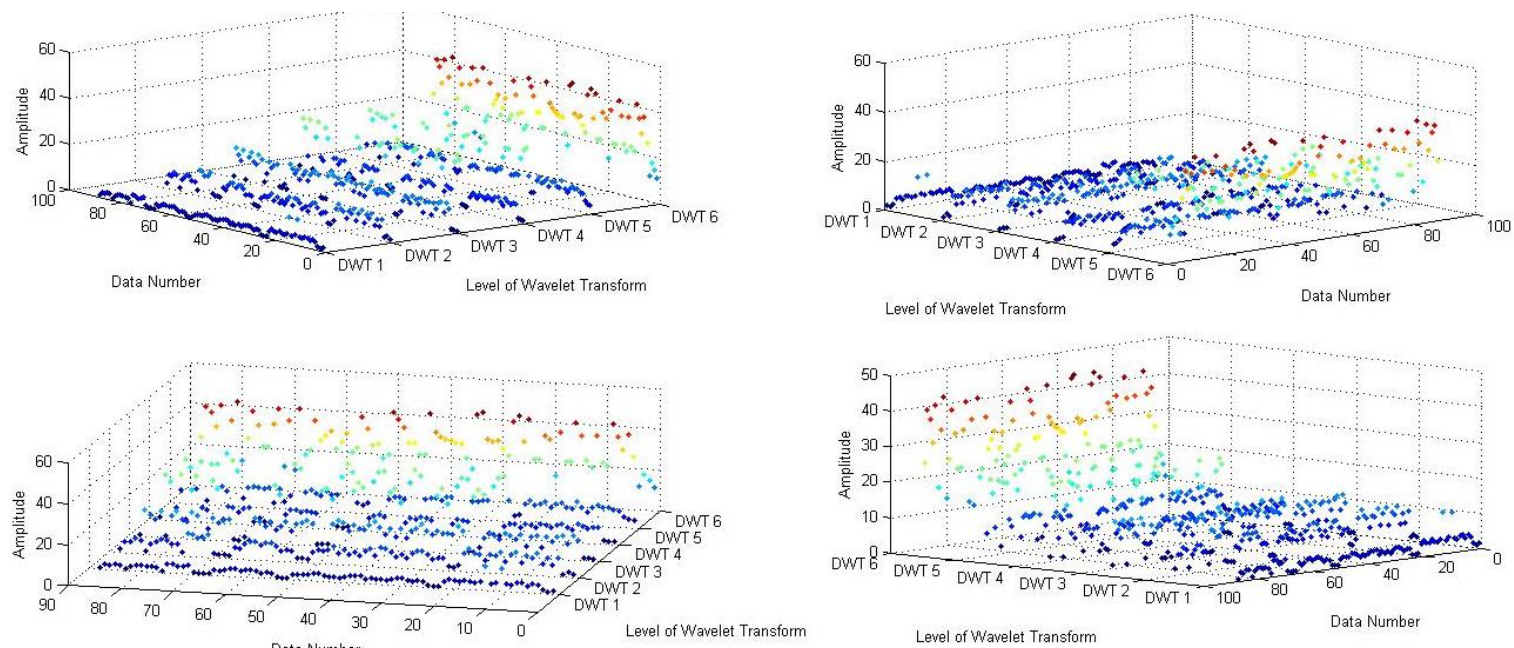

Figure 8. Overlap between neural network training in different speeds
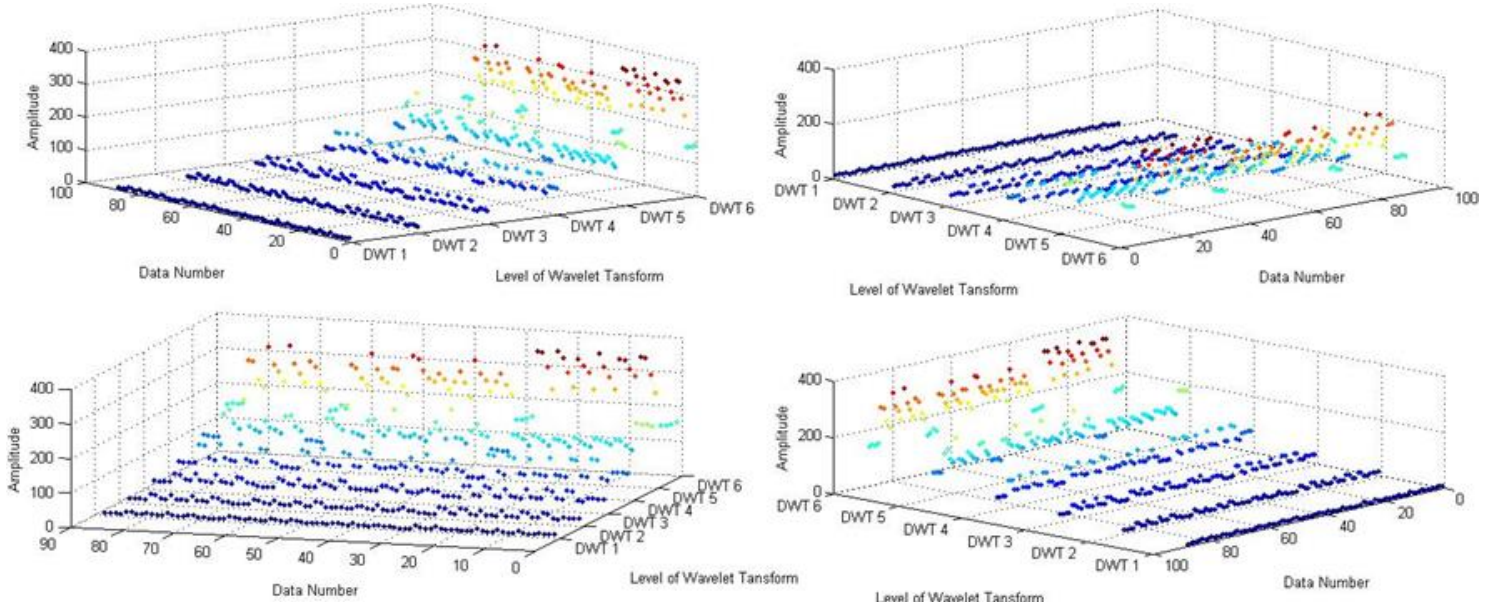

Figure 9. Overlap between neural network training in different loads

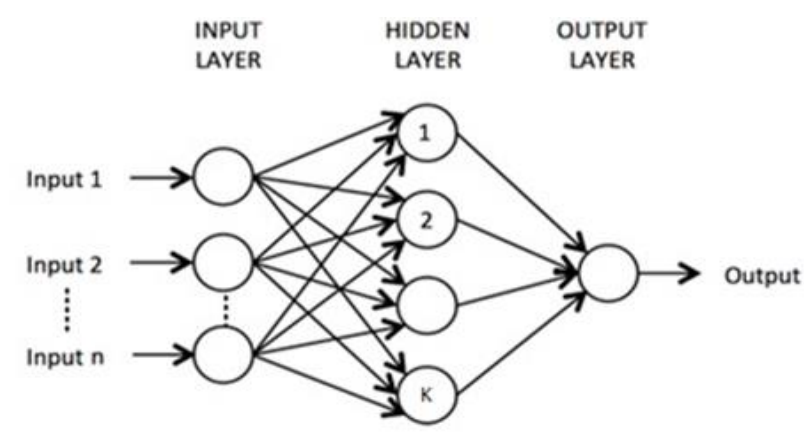

Figure 10. Example of feed forward neural network

Neurons form the Building of the neural network. As shown in Figure 9, we can have the number of $\mathrm{n}$ for input and $\mathrm{k}$ for the hidden layer which $\mathrm{n}$ and $\mathrm{k}$ are not equal. Inputs $\mathrm{P} 1, \mathrm{P} 2, \mathrm{P} 3, \ldots, \mathrm{Pn}$ in the matrix $\mathrm{W}$ is 
the weight matrix in here is multiplied and then gathers in the sum $(\Sigma)$, the sum is always entered in the excitation function $f$ with a bias neuron $b$.

$$
\mathrm{y}=\mathrm{W}_{1,1} \times \mathrm{P}_{1}+\mathrm{W}_{1,2} \times \mathrm{P}_{2}+\cdots+\mathrm{W}_{1, \mathrm{R}} \times \mathrm{P}_{\mathrm{R}}+\mathrm{b}
$$

The above formula can be simpler:

$\mathrm{y}=\mathrm{W} \times \mathrm{P}+\mathrm{b}$

In this paper, a neural network with two layers is used which the first layer has 60 levels and the second layer has 7 levels for classification and identification of open-circuit fault.

\subsection{Fault Detection Strategy and Algorithm}

Processes and strategies to identify and classify faults are defined as follows. First, the system was tested in a wide range of load and a different speed for healthy and faulty states: S1, S2 ... S6, S1S2 ... S3S4 ... S5S6. View of the test conditions authentication system is considered for each fault and it is shown in Figure 11. Neural network outputs are as binary numbers and their number depends on the number of fault conditions. In this paper, the target system has been tested in two different operating conditions and in 110 cases. Thus we have 7 output neural network. Three-phase current is measured in all cases. The wavelet transform is applied in all the three-phase current for extracting signal characteristics to identify the faults. With using open-circuit fault detection pattern introduced in this paper, we calculated the obtained the wavelets mean energy. Matrix [A] is formed with consists of average wavelet energy in different states of the system operation. Because of the sparse matrix numbers and ease the process of fault classification, it is used linear normalization in order to put the numbers in a range of matrixes.
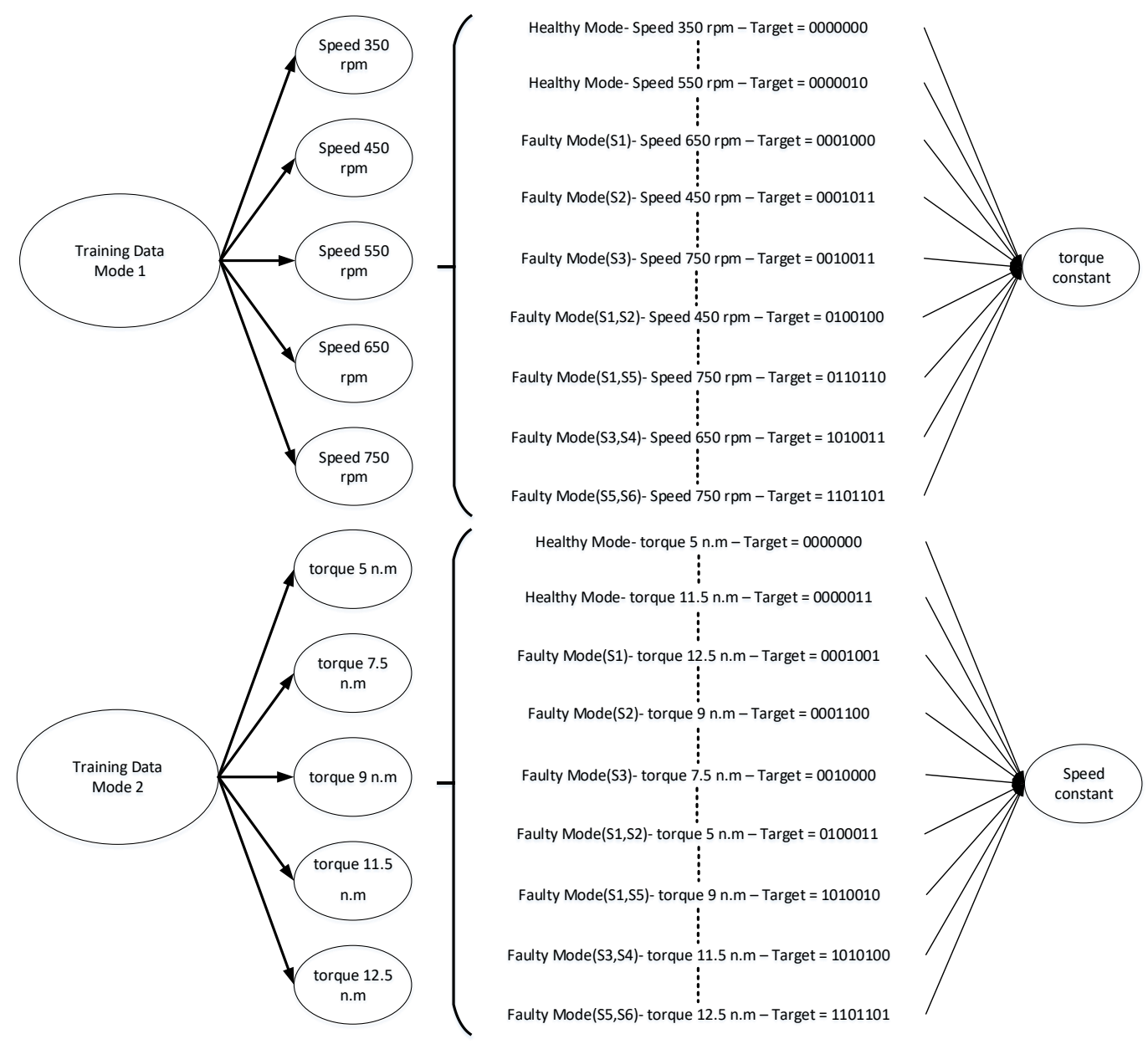

Figure 11. Considered system test condition and its output for each fault

An open-circuit Fault detection method with wavelet transform in IGBT-based ... (Seyed Saeid Moosavi) 


\subsection{Training the Neural Network}

The data discussed in this article is a total of 220 which 110 of them is for speed changing conditions and 110 of them is for load changing conditions. Discussed faults are unique and dual IGBT opencircuit faults. $75 \%$ of this data is to train the neural network and the remaining 25 percent is for neural network testing data. To ensure the proposed method, we tested this method 20 times. The results yielded 99\% accuracy for us. Figure 12 shows the classification neural network training data. The regression obtained from the trained neural network is shown in Figure 13.

The output of which is obtained from the training neural networks consists of classified faults is shown in Figure 11. In this output, the location of each fault is classified based on the target position in the matrix. The obtained results are used in the process of isolating the power system from fault and eliminate the error. A few examples of the output of neural networks in different states of the system are given in Table 1 and 2. According to the fault diagnosing strategy, 7 output for the neural network is regulated.

As it is shown in the Table 1 and Table 2, all types of faults in different operating conditions have been detected and identified. The output of the neural network is used in order to control of fault and isolating system from that.

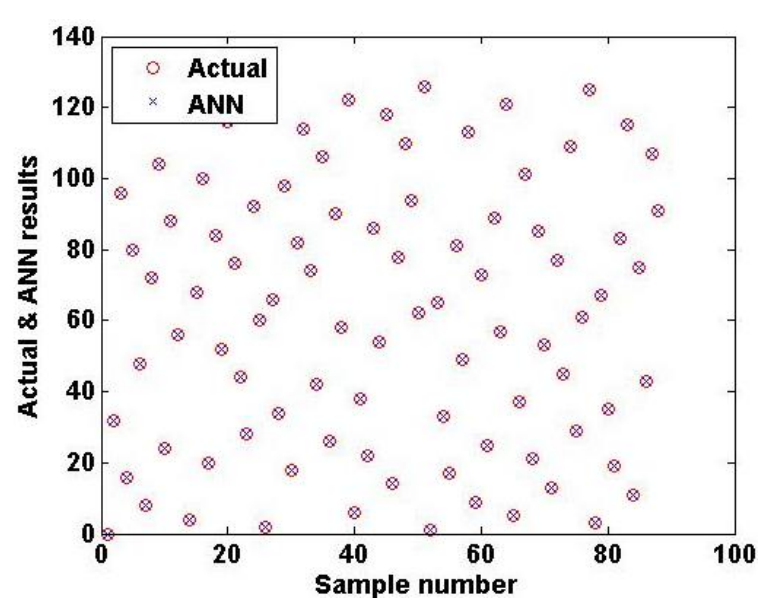

Figure 12. Neural network data for training

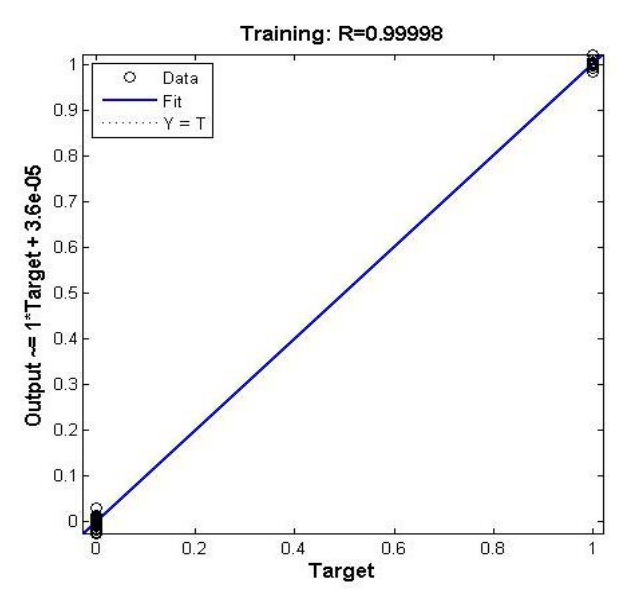

Figure 13. Regression obtained from trained neural network

Table 1. Neural Network Output In Different Fault Types In Operating System With Variable Speed And Constant Torque

\begin{tabular}{|c|c|c|c|c|c|c|c|c|}
\hline Fault Mode & Output1 & Output2 & Output3 & Output4 & Output5 & Output6 & Output7 & Detection \\
\hline Healthy & 0 & 0 & 0 & 0 & 0 & 0 & 0 & $\mathrm{~T}$ \\
\hline Healthy & 0 & 0 & 0 & 0 & 0 & 1 & 0 & $\mathrm{~T}$ \\
\hline S1 & 0 & 0 & 0 & 1 & 0 & 0 & 0 & $\mathrm{~T}$ \\
\hline $\mathrm{S} 2$ & 0 & 0 & 0 & 1 & 0 & 1 & 1 & $\mathrm{~T}$ \\
\hline S3 & 0 & 0 & 1 & 0 & 0 & 1 & 1 & $\mathrm{~T}$ \\
\hline $\mathrm{S} 1, \mathrm{~S} 2$ & 0 & 1 & 0 & 0 & 1 & 0 & 0 & $\mathrm{~T}$ \\
\hline $\mathrm{S} 3, \mathrm{~S} 4$ & 1 & 0 & 1 & 0 & 0 & 1 & 1 & $\mathrm{~T}$ \\
\hline S1,S5 & 0 & 1 & 1 & 0 & 1 & 1 & 0 & $\mathrm{~T}$ \\
\hline S3,S6 & 1 & 0 & 1 & 1 & 0 & 1 & 0 & $\mathrm{~T}$ \\
\hline
\end{tabular}

Table 2. Neural Network Output In Different Fault Types In Operating System With Constant Speed And Variable Torque

\begin{tabular}{ccccccccc}
\hline Fault Mode & Output1 & Output2 & Output3 & Output4 & Output5 & Output6 & Output7 & Detection \\
\hline Healthy & 0 & 0 & 0 & 0 & 0 & 0 & 0 & T \\
Healthy & 0 & 0 & 0 & 0 & 0 & 1 & 1 & T \\
S1 & 0 & 0 & 0 & 0 & 1 & 1 & 0 & T \\
S2 & 0 & 0 & 0 & 1 & 1 & 0 & 0 & T \\
S3 & 0 & 0 & 1 & 0 & 0 & 0 & 1 & T \\
S1,S2 & 0 & 1 & 0 & 0 & 1 & 0 & 0 & T \\
S3,S4 & 1 & 0 & 1 & 0 & 1 & 0 & T \\
S1,S5 & 0 & 1 & 1 & 0 & 1 & 0 & 0 & T \\
S3,S6 & 1 & 0 & 1 & 1 & 1 & 0 & &
\end{tabular}




\section{CONCLUSION}

In this paper, identifying and detecting IGBT open-circuit fault in a DC/AC inverter of electric car traction drive examined and studied. The proposed inverter is a voltage source inverter and is used to drive a PMSM motor. Fault characteristic in the different operating condition in both constant/variable loads and constant/variable speed have been studied in this paper. We used three phase current and wavelet transform in order to detect and extract fault characteristics. A pattern for extracting fault characteristic from wavelet transform was introduced. The performance of proposed model was examined in different operational conditions which the results, were satisfied. Finally, the multilayer neural network algorithm is used for the detection and classification of faults. In the paper, all the 220 healthy and faulty state identified with good accuracy after applying wavelet transform and proposed fault detecting pattern.

\section{ACKNOWLEDGEMENTS} (CISSC)

This work has been supported by the Center for International Scientific Studies \& Collaboration

\section{REFERENCES}

1- M. F. Habban, M. Manap, A. R. Abdullah, M. H. Jopri, T. Sutikno, "An Evaluation of Linear Time Frequency Distribution Analysis for VSI Switch Faults Identification", International Journal of Power Electronics and Drive System (IJPEDS), March 2017, Vol. 8, No. 1, pp. 1 9.

2- Handbook for Robustness Validation of Automotive Electrical/Electronic Modules. Frankfurt, Germany: ZVEL, Jun. 2008.

3- H. Wang, K. Ma, and F. Blaabjerg, "Design for reliability of power electronic systems" in Proc. Ind. Electron. Soc. Conf., 2012, 33-44.

4- Milad Falahi, Hung-Ming Chou, Mehrdad Ehsani, Le Xie and Karen L. Butler-Purry, "Potential Power Quality Benefits of Electric Vehicles", IEEE TRANSACTIONS ON SUSTAINABLE ENERGY, OCTOBER 2013, 4(4), 10161023.

5- Ui-Min Choi, Frede Blaabjerg, Kyo-Beum Lee, "Study and Handling Methods of Power IGBT Module Failures in Power Electronic Converter Systems", IEEE TRANSACTIONS ON POWER ELECTRONICS, MAY 2015, 30(5), $2517-2533$.

6- Tianzhen Wang, JieQi, HaoXu, YideWang, LeiLiu, DijuGao, "Fault diagnosis method based on FFT-RPCASVM for Cascaded-Multilevel Inverter", ISA Transactions, January 2016, 60, 156-163.

7- R. Peuget, S. Courtine and J. P. Rognon, "Fault detection and isolation on a PWM inverter by knowledge-based model" , 1998, IEEE Trans. Ind. Appl. , 34(6), 1318 -1326.

8- B. Boudjellal, T. Benslimane, "Open-switch Fault-tolerant Control of Power Converters in a Grid-connected Photovoltaic System", International Journal of Power Electronics and Drive System (IJPEDS), December 2016, 7(4), 1294 1308

9- F. Zidani, D. Diallo, M. Benbouzid and R. Nait-Said, "A fuzzy-based approach for the diagnosis of fault modes in a voltage-fed PWM inverter induction motor drive", 2008, IEEE Trans. Ind. Electron. , 55(2), 86 -593.

10- R. L. A. Ribeiro , C. B. Jacobina, E. R. C. Silva and A. M. N. Lima , "Fault detection of open-switch damage in voltage-fed PWM motor drive systems", 2003, IEEE Trans. Power Electron., 18(2) , 587 -593.

11- Q.-T. An, L.-Z. Sun and T. M. Jahns, "Low-cost diagnostic method for open-switch faults in inverters", 2010, Electron. Lett. , 46(14), 1021 -1022.

12- Zhenyou Zhang, Yi Wang, Kesheng Wang, "Fault diagnosis and prognosis using wavelet packet decomposition, Fourier transform and artificial neural network", Journal of Intelligent Manufacturing December 2013, 24(6), 12131227.

13- Dima Fares ,Riad Chedid ,Ferdinand Panik ,Sami Karaki, Rabih Jabr, "Dynamic programming technique for optimizing fuel cell hybrid vehicles", international journal of hydrogen energy (2015).

14- Mario Marchesoni and Camillo Vacca, "New DC-DC Converter for Energy Storage System Interfacing in Fuel Cell Hybrid Electric Vehicles", IEEE TRANSACTIONS ON POWER ELECTRONICS, January 2007, 22(1), 301-308.

15- Zedong Zheng, Kui Wang, Lie Xu, Yongdong Li, "A Hybrid Cascaded Multi-level Converter for Battery Energy Management Applied in Electric Vehicles", IEEE Transactions on Power Electronics, 2014, 29(7), 3537-3546.

16- A. Haddoun, M.E.H. Benbouzid, D. Diallo, R. Abdessemed, J. Ghouili5 and K. Srairi, "Comparative Analysis of Control Techniques for Efficiency Improvement in Electric Vehicles", IEEE Conference on Vehicle Power and Propulsion, VPPC 2007, 629-634.

17- Y. Gu, Y. Sh1, J. Wang, "Sensorless vector control of AC servo system with artificial neural network observer and fuzzy speed controller", Przeglad Electrotechniczny, 2012, 150-153.

18- Y-S. Kung, M-S. Wang, C-C. Huang, "DSP-based Adaptive Fuzzy Control for a Sensorless PMSM Drive”, Control and Decision Conference, 2009, 2379-2384. 
19- T. Ming, G. Lin, L. Deliang, "Sensorless permanent magnet synchronous motor drive using an optimized and normalized extended Kalman filter", International Conference on Electric Machines and Systems, 2011, 1-4.

20- M. Muenchof, M. Beck, R. Isermann, "Fault -tolerant actuators and drives-structures, fault detection principles and applications", Elsevier Annual Reviews in Control, 2009, 33(2), 136- 148.

21- M. Thuillard, "A review of wavelet networks, wavenets, fuzzy Wavenets and their applications", Proceeding ESIT 2000, 14-15 September 2000, Aachen, Germany.

22- S. Saeid. Moosavi, A. Djerdir, Y. Ait-Amirat, D. A. Khaburi, "Fault Detection In 3-Phase Traction Motor Using Artificial Neural Networks", 2012 IEEE Transportation Electrification Conference and Expo (ITEC 2012)Michigan, USA.

23- S. Saeid. Moosavi, A. Djerdir, Y. Ait-Amirat, D. A. Khaburi, "Artificial Neural Networks Based Fault Detection in 3-Phase PMSM Traction Motor", IEEE XXth International Conference on Electrical Machines (ICEM'2012), Septembre 2-5-2012, Marseille, France.

24- Souha Boukadida, Soufien Gdaim, Abdellatif Mtiba, "Sensor Fault Detection and Isolation Based on Artificial Neural Networks and Fuzzy Logic Applicated on Induction Motor for Electrical Vehicle", International Journal of Power Electronics and Drive System (IJPEDS), June 2017, 8(2), 601 611.

25- S. Saeid. Moosavi, A. Djerdir, Y. A. Amirat, D. A. Khaburi, "Artificial Neural Network-based Fault Diagnosis in the AC-DC Converter of the Power Supply of Series Hybrid Electric Vehicle", IET Electrical Systems in Transportation, 2016, 6(2), 96 - 106.

26- Mahmood Moghadasian, Seyed Mohammad Shakouhi, Seyed Saeid Moosavi, "Induction motor fault diagnosis using ANFIS based on vibration signal spectrum analysis", 3rd International Conference on Frontiers of Signal Processing (ICFSP), 2017,105-108.

\section{BIOGRAPHIES OF AUTHORS}

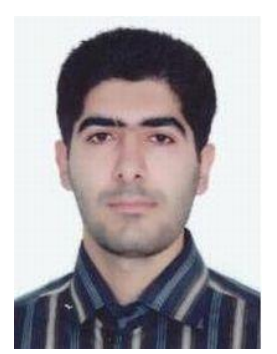

Seyed Saeid Moosavi (S’09) was born in Amol, Iran. He received the B.Sc. degree in electrical power engineering, in 2004, the M.Sc. degree from the Electrical Railway engineering department of Iran University of science and technology (IUST), Tehran, Iran, in 2009. From 2007-2010 he was a researcher on Electrification, control and signaling of railway transportation He received the PHD in electrical engineering at university of technology Belfort Montbeliard, in 2013. He was assistant professor in the Systems and Transport (SET) laboratory at University of Technology Belfort Montbéliard, France and researcher in the FEMTO-ST laboratory in 2014. Now he is assistant profsor of Amol university of special modern technologies. His main research interests include the modeling of electrical machines (EM), hybrid/electric vehicle $(\mathrm{H} / \mathrm{EV})$ and the study and application of, condition monitoring, signal processing, fault detection and diagnosis techniques for EM and $\mathrm{H} / \mathrm{EV}$.

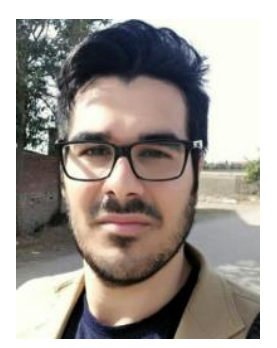

Hessam Akbari was born in 1994, Amol, Mazandaran. He received the B.Sc. degree in electrical power engineering from 2011-2015. Now he enrolls as Master's Student in Kavosh institute (Iran). His research is about Fault diagnosis, and signal processing on EV component.

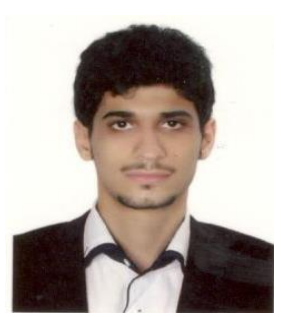

Saeed Valipour was born in 1994, Talesh, Gilan. He received the B.Sc. degree in electrical power engineering, in 2015 in Electrical Engineering from Shahid Beheshti University (Iran) From 2011-2015. Now he enrolls as Master's Student in Iran University of Science and Technology (Iran). His research is about Fault-tolerant in multilevel inverters. 